\title{
Dietary L-threonine supplementation attenuates lipopolysaccharide-induced inflammatory responses and intestinal barrier damage of broiler chickens at an early age
}

\author{
Yueping Chen, Hao Zhang, Yefei Cheng, Yue Li, Chao Wen and Yanmin Zhou* \\ College of Animal Science and Technology, Nanjing Agricultural University, Nanjing 210095, People's Republic of China \\ (Submitted 11 October 2017 - Final revision received 24 February 2018 - Accepted 26 February 2018)
}

\begin{abstract}
This study was conducted to investigate the protective effects of L-threonine (L-Thr) supplementation on growth performance, inflammatory responses and intestinal barrier function of young broilers challenged with lipopolysaccharide (LPS). A total of 144 1-d-old male chicks were allocated to one of three treatments: non-challenged broilers fed a basal diet (control group), LPS-challenged broilers fed a basal diet without L-Thr supplementation and LPS-challenged broilers fed a basal diet supplemented with $3.0 \mathrm{~g} / \mathrm{kg} \mathrm{L}$-Thr. LPS challenge was performed intraperitoneally at 17, 19 and $21 \mathrm{~d}$ of age, whereas the control group received physiological saline injection. Compared with the control group, LPS challenge impaired growth performance of broilers, and L-Thr administration reversed LPS-induced increase in feed/gain ratio. LPS challenge elevated blood cell counts related to inflammation, and pro-inflammatory cytokine concentrations in serum (IL- $1 \beta$ and TNF- $\alpha$ ), spleen (IL-1 $\beta$ and TNF- $\alpha$ ) and intestinal mucosa (jejunal interferon- $\gamma$ (IFN- $\gamma$ ) and ileal IL- $1 \beta$ ). The concentrations of intestinal cytokines in LPSchallenged broilers were reduced by L-Thr supplementation. LPS administration increased circulating D-lactic acid concentration, whereas it reduced villus height, the ratio between villus height and crypt depth and goblet density in both jejunum and ileum. LPS-induced decreases in jejunal villus height, intestinal villus height:crypt depth ratio and ileal goblet cell density were reversed with L-Thr supplementation. Similarly, LPS-induced alterations in the intestinal mRNA abundances of genes related to intestinal inflammation and barrier function (jejunal toll-like receptor $4, I F N-\gamma$ and claudin-3, and ileal $I L-1 \beta$ and zonula occludens-1) were normalised with L-Thr administration. It can be concluded that L-Thr supplementation could attenuate LPS-induced inflammatory responses and intestinal barrier damage of young broilers.
\end{abstract}

Key words: L-Threonine: Lipopolysaccharides: Inflammatory responses: Intestinal barriers: Broilers

Bacterial lipopolysaccharide (LPS), a complex glycolipid, is the major component of the outer surface membrane in almost all gram-negative bacteria, and it can trigger inflammatory responses in diverse eukaryotic species ranging from insects to humans by activating signal pathways and promoting gene expressions, which are involved in the regulation of immune system and inflammation ${ }^{(1,2)}$. In broiler chickens, an enormous amount of research has shown that immunological stress mimicked by administrating LPS intraperitoneally or intravenously could induce acute inflammatory responses, stimulate synthesis of pro-inflammatory cytokines and impair nutrient adsorption, which ultimately contribute to compromised growth performance of LPS-challenged broilers ${ }^{(3-8)}$. Aside from inducing inflammation, LPS challenge would also damage intestinal barrier function ${ }^{(9)}$, a key factor associated with intestinal and body's health maintenance ${ }^{(10)}$. Wu et al. ${ }^{(11)}$ have reported that LPS challenge to young broiler chickens impairs growth performance and increases circulating D-lactic acid (D-LA) level and diamine oxidase (DAO) activity, which are two sensitive biomarkers reflecting gut permeability. Similarly, our previous results reveal that LPS-challenged broilers exhibit impaired intestinal morphology, increased plasma DAO activity and altered mRNA expressions of tight-junction proteins in both jejunum and ileum, when compared with their unchallenged counterparts $^{(4)}$. To maintain growth performance and welfare of broilers, it is therefore necessary to apply nutritional interventions in broiler production in order to alleviate the harmful consequences of bacterial LPS challenge.

Threonine (Thr), an indispensable amino acid for humans and animals, plays a vital role in the synthesis of Ig and gut mucosal proteins $^{(12-14)}$. In mammals, about $50 \%$ of dietary Thr is utilised by gut to synthesise various mucosal proteins, particularly mucins, and this ratio would increase for young animals ${ }^{(14-16)}$. Dietary Thr restriction could reduce mucin synthesis, inhibit

Abbreviations: ADFI, average daily feed intake; ADG, average daily gain; CLDN, claudin; DAO, diamine oxidase; D-LA, D-lactic acid; F:G, feed:gain ratio; IFN- $\gamma$, interferon- $\gamma$; LPS, lipopolysaccharide; L-thr, L-threonine; MUC2, mucin 2; MyD88, myeloid differentiation factor 88; NRC, National Research Council; OCLN, occludin; TFF2, trefoil factor 2; TLR4, toll-like receptor 4; ZO-1, zonula occludens-1.

* Corresponding author: Y. Zhou, fax +86 25 84395314; email zhouym6308@163.com 
goblet cell differentiation and finally impair intestinal barrier function of pigs ${ }^{(17-19)}$ or broilers ${ }^{(20-22)}$. Moreover, Thr deficiency could exacerbate inflammatory responses and worsen the gut barrier impairment of broilers under the combined feed withdrawal and coccidial infection challenge ${ }^{(22)}$ or coccidiosis challenge $^{(23)}$. Usually, Thr level in the maize-soyabean meal diet ranges from 7.5 to $8.3 \mathrm{~g} / \mathrm{kg}$, which can almost meet the requirement of National Research Council (NRC) ${ }^{(24)}$ for broiler chickens. Previous studies have proven that Thr requirement of broilers increases when reared under stress and non-hygienic conditions $^{(25,26)}$, and it is beyond the NRC recommendation to acquire the optimal immune response ${ }^{(27)}$. Recently, Min et al. ${ }^{(28)}$ have concluded that Thr requirement of broilers for the optimum gut morphology and antioxidant capacity is $125 \%$ of NRC recommendation during a 42-d assay. Similarly, our recent results have revealed that the supplementation of $\mathrm{L}$-Thr to a basal diet that could meet NRC recommendation of Thr, especially at a dosage of $3.0 \mathrm{~g} / \mathrm{kg}$, can improve intestinal morphology and caecal microflora composition, promote intestinal goblet cell density and beneficially modulate expressions of genes related to intestinal immunity and barrier function of broilers at an early age ${ }^{(29)}$. A higher level of dietary Thr level would also relieve inflammatory responses and intestinal barrier damage of broilers under pathogenic bacteria challenge ${ }^{(22,23)}$. In a chicken intestinal ex vivo model with LPS challenge, Zhang et al ${ }^{(30)}$ have recently reported that Thr deprivation in culture medium impairs inflammatory and secretory immune responses, and culture of explants from birds fed a Thr-adequate diet is more responsive to LPS challenge than explants from birds fed a Thr-deficient diet, as evidenced by increased mRNA abundances of mucin 2 (MUC2), IL-8 and IgA. These results in turn suggest that a higher level of dietary Thr is required for LPS-challenged broilers. However, in vivo studies investigating the protective effects of dietary L-Thr supplementation on broilers challenged with LPS are absent. According to our previous results ${ }^{(29)}$ and the finding of other researchers ${ }^{(28)}$, we supplemented $3.0 \mathrm{~g} / \mathrm{kg}$ L-Thr to a control diet that met the NRC requirement of Thr for broilers, and then investigated whether this supplementation would bring beneficial consequences on the growth performance, inflammatory responses and intestinal barrier function of LPS-challenged broiler chickens at an early age.

\section{Methods}

\section{Animals and treatment}

The experimental protocols were in accordance with guidelines set by Nanjing Agricultural University Institutional Animal Care and Use Committee. A total of 144 1-d-old male broiler chicks (Arbor Acres Plus) were purchased from a local hatchery. After weighing, chicks were allocated to one of three treatments, with each treatment being composed of six replicates (cages) of eight birds each. The initial body weight of chicks was similar among cages. The three experimental treatments were as follows: (1) non-challenged broilers given a basal diet (control group); (2) LPS-challenged broilers given a basal diet (LPS challenge group); and (3) LPS-challenged broilers fed a basal diet supplemented with $3.0 \mathrm{~g} / \mathrm{kg}$ L-Thr crystals (L-Thr administration group; the purity of L-Thr crystals is $98.5 \%$; Meihua
Holdings Group Co., Ltd). The supplemental L-Thr level was optimised according to previous results ${ }^{(28,29)}$. This experiment lasted for a total of $21 \mathrm{~d}$ (from 1 to $21 \mathrm{~d}$ of age). LPS from Escherichia coli (serotype O55.B5; Sigma-Aldrich) was dissolved in $0.86 \%(\mathrm{w} / \mathrm{v})$ sterile saline solution to prepare $1 \mathrm{mg} / \mathrm{ml}$ LPS solution. At 17, 19 and $21 \mathrm{~d}$ of age, broilers were intraperitoneally injected with LPS solution at a dosage of $1 \mathrm{ml} / \mathrm{kg}$ of body weight or equivalent volume of $0.86 \%$ sterile saline solution (control treatment). The dosage of LPS and its administration routine adopted in this study were referred to available findings ${ }^{(3,31,32)}$. Ingredient composition and nutrient level of the basal diet are presented in the Table 1 . The calculated Thr level $(8.00 \mathrm{~g} / \mathrm{kg})$ in the basal diet $100 \%$ met the NRC recommendation for broilers during 1 to $21 \mathrm{~d}$ of age ${ }^{(24)}$. The analysed $\mathrm{Thr}$ concentration that was measured by an automatic Hitachi L-8900 amino acid analyzer (Hitachi) in the control group, LPS challenge group and the L-Thr administration group was $7 \cdot 84$, 7.76 and $10.43 \mathrm{~g} / \mathrm{kg}$, respectively. The diets were prepared isonitrogenously by supplementing the basal diet (control group and LPS challenge group) with approximate $2.3 \mathrm{~g} / \mathrm{kg}$ L-alanine (98.5\%; Sigma-Aldrich). Birds were housed in threelevel cages $(120 \times 60 \times 50 \mathrm{~cm})$, and had ad libitum access to mash feed and water in a temperature- and light-controlled facility with a light schedule of $23 \mathrm{~h}$ light and $1 \mathrm{~h}$ darkness. The temperature of the chicken house was maintained between 32

Table 1. Composition and nutrient level of the basal diet $(\mathrm{g} / \mathrm{kg}$, as fed basis unless otherwise stated)

\begin{tabular}{|c|c|}
\hline Items & $1-21 d$ \\
\hline \multicolumn{2}{|l|}{ Ingredients } \\
\hline Maize & $576 \cdot 10$ \\
\hline Soyabean meal & $310 \cdot 00$ \\
\hline Maize gluten meal & 32.90 \\
\hline Soyabean oil & $31 \cdot 10$ \\
\hline Limestone & 12.00 \\
\hline Dicalcium phosphate & 20.00 \\
\hline L-Lys & 3.40 \\
\hline DL-Met & 1.50 \\
\hline Sodium chloride & 3.00 \\
\hline Premix ${ }^{*}$ & $10 \cdot 00$ \\
\hline \multicolumn{2}{|l|}{ Calculated nutrient levels } \\
\hline Apparent metabolisable energy $(\mathrm{MJ} / \mathrm{kg})$ & $12 \cdot 56$ \\
\hline Crude protein & 210.98 \\
\hline $\mathrm{Ca}$ & 9.97 \\
\hline Available P & 4.57 \\
\hline Lys & 11.98 \\
\hline Met & 4.97 \\
\hline Met + Cys & 8.49 \\
\hline Thr & 8.00 \\
\hline Digestible Lys & $11 \cdot 10$ \\
\hline Digestible Met & 4.72 \\
\hline Digestible Met + Cys & 7.85 \\
\hline Digestible Thr & 7.03 \\
\hline \multicolumn{2}{|l|}{ Analysed composition } \\
\hline Crude protein & $205 \cdot 14$ \\
\hline Thr & 7.84 \\
\hline Met & 4.86 \\
\hline
\end{tabular}

* Premix provided per $\mathrm{kg}$ of diet: vitamin A (transretinyl acetate), $3.44 \mathrm{mg}$; vitamin $\mathrm{D}_{3}$ (cholecalciferol), $0.075 \mathrm{mg}$; vitamin E (all-rac- $\alpha$-tocopheryl acetate), $30 \mathrm{mg}$; menadione, $1.3 \mathrm{mg}$; thiamin, $2.2 \mathrm{mg}$; riboflavin, $8 \mathrm{mg}$; nicotinamide, $40 \mathrm{mg}$; choline chloride, $600 \mathrm{mg}$; calcium pantothenate, $10 \mathrm{mg}$; pyridoxine. $\mathrm{HCl}, 4 \mathrm{mg}$; biotin, $0.04 \mathrm{mg}$; folic acid, $1 \mathrm{mg}$; vitamin $\mathrm{B}_{12}$ (cobalamin), $0.013 \mathrm{mg}$; $\mathrm{Fe}$ (from ferrous sulphate), $80 \mathrm{mg}$; $\mathrm{Cu}$ (from copper sulphate), $8.0 \mathrm{mg}$; $\mathrm{Mn}$ (from manganese sulphate), $110 \mathrm{mg} ; \mathrm{Zn}$ (from zinc oxide), $60 \mathrm{mg}$; iodine (from calcium iodate), $1.1 \mathrm{mg}$; $\mathrm{Se}$ (from sodium selenite), $0.3 \mathrm{mg}$. 
and $34^{\circ} \mathrm{C}$ for the initial $3 \mathrm{~d}$, and it was then decreased by 2 to $3^{\circ} \mathrm{C}$ each week until a final temperature of $26^{\circ} \mathrm{C}$ was achieved. Mean relative humidity was kept approximately at $70 \%$ for the first $3 \mathrm{~d}$, and maintained at $60-65 \%$ thereafter.

\section{Sample collection}

At $21 \mathrm{~d}$ of age, one bird in each cage (replicate) with a body weight close to the mean body weight in the respective cage was selected and weighed immediately after LPS challenge ( ix birds per treatment, and eighteen birds in total). Wholeblood samples were collected in both glass anti-coagulant tubes coated with EDTA and tubes without anti-coagulant by wing vein puncture, and kept refrigerated until analysis. Serum was then separated from blood samples collected from wing vein after centrifugation at $4450 \mathrm{~g}$ for $15 \mathrm{~min}$ at $4^{\circ} \mathrm{C}$, and it was immediately frozen at $-20^{\circ} \mathrm{C}$ until subsequent analysis. After blood collection, the birds were euthanised by cervical dislocation, and necropsy was carried out. The jejunum (from the end of the duodenum to the Meckel's diverticulum) and ileum (from Meckel's diverticulum to the ileocecal junction) samples were immediately dissected free from mesentery and the connective tissues, and placed on a chilled stainless steel tray. About 2-cm segments of mid-jejunum and mid-ileum were then excised, flushed gently and repeatedly with ice-cold PBS ( $\mathrm{pH} 7.4$ ) and immediately immersed in $10 \%$ fresh (w/v), chilled neutral-buffered formalin solution for subsequent histological measurement. The remaining jejunal and ileal segments were opened longitudinally, and washed with ice-cold PBS to remove digesta. The jejunal and ileal mucosa was then scratched carefully using a sterile glass microscope slide and collected into sterile frozen tubes, which was snapped in liquid $\mathrm{N}_{2}$ and stored at $-80^{\circ} \mathrm{C}$ for further analysis. Longitudinal sections of spleen (about $0.5 \mathrm{~g}$ ) were also collected and store at $-80^{\circ} \mathrm{C}$ after freezing in liquid $\mathrm{N}_{2}$.

\section{Growth performance determination}

At 16 and $21 \mathrm{~d}$ of age, birds were weighed after a 12-h feed deprivation period (the last LPS injection and birds selection for sampling at $21 \mathrm{~d}$ of age were performed at early morning (approximately 05.30 hours) before the 12-h feed withdrawal of broilers to avoid intestinal barrier impairment induced by feed deprivation), and the total feed consumption by the birds on a cage (replicate) basis was recorded to calculate average daily gain (ADG), average daily feed intake (ADFI) and feed:gain ratio (F:G). The spilled feed in the steel tray placed under the cage was carefully removed and weighed, which was considered as feed wastage. Birds that died during the experiment were weighed, and the data were included when calculating F:G.

\section{Blood cell count assay}

The whole-blood samples collected in the EDTA anti-coagulant tubes were used to determine the numbers of leucocytes, lymphocytes, mononuclear cells, neutrophils, eosinophils and erythrocytes, using an automatic blood counter (KT6180; Genrui Biotech Inc.) with adapted dilutions in the Animal Hospital of Nanjing Agricultural University.
Measurement of serum D-lactic acid level and diamine oxidase activity

The serum D-LA concentration was quantified using a D-LA colorimetric assay kit (catalogue no. K667-100; BioVision Inc.) according to the manufacturer's protocols, and its determination range was $0 \cdot 01-10 \mathrm{mmol} / \mathrm{l}$. The DAO activity in the serum was measured according to the spectrophotometric method described by Hosoda et $a l{ }^{(33)}$. In brief, a $0.5-\mathrm{ml}$ serum sample was added to the assay mixture containing $3.0 \mathrm{ml}$ of PBS $(0.2 \mathrm{~mol} / \mathrm{l}$, $\mathrm{pH} 7 \cdot 2), 0.1 \mathrm{ml}$ of horseradish peroxidase solution $(0.04 \mathrm{~g} / \mathrm{l})$, $0.1 \mathrm{ml}$ of $\mathrm{o}$-dianisidine-methanol solution $(5 \mathrm{~g} / \mathrm{l}$ odianisidine in methanol) and $0.1 \mathrm{ml}$ of substrate solution $(1.75 \mathrm{~g} / \mathrm{l}$ cadaverine dihydrochloride). The absorbance of reaction mixture at $436 \mathrm{~nm}$ was measured spectrophotometrically after incubation at $37^{\circ} \mathrm{C}$ for $0.5 \mathrm{~h}$ to calculate serum DAO activity. The reagents used in DAO activity assay were sourced from Sigma-Aldrich.

\section{Determination of pro-inflammatory cytokines}

Before measurement, approximately $0.3 \mathrm{~g}$ of tissue samples (spleen, and jejunal and ileal mucosa) were homogenised in an ice-cold bath with a chilled $154 \mathrm{mmol} / 1$ sterile sodium chloride solution (1:9, w/v) for $30 \mathrm{~s}$, using a PRO-PK-02200D homogenizer (Pro Scientific, Inc.). After that, the homogenisation was centrifuged at $4450 \boldsymbol{g}$ for $15 \mathrm{~min}$ at $4^{\circ} \mathrm{C}$, and the resulting supernatant was collected in five aliquots, which were immediately stored at $-20^{\circ} \mathrm{C}$ until the subsequent analysis. The levels of interferon- $\gamma$ (IFN- $\gamma$ ), IL- $1 \beta$ (IL- $1 \beta)$ and TNF- $\alpha$ (TNF- $\alpha)$ in the serum, spleen and intestinal mucosa samples were measured by ELISA using chicken-specific IFN- $\gamma$ (catalogue no. H025), IL-1 $\beta$ (catalogue no. H002) and TNF- $\alpha$ (catalogue no. H052) quantification kits (Nanjing Jiancheng Bioengineering Institute) based on the manufacturer's instructions. The inter- and intra-assay CV were $<8$ and $10 \%$, respectively. All results were normalised against total protein level in each sample for inter-sample comparison. The total protein content in the spleen and mucosa samples was measured by Bradford method, using crystalline bovine serum albumin (Sigma-Aldrich) as the standard protein.

\section{Histological measurement}

Collected intestinal segments were transferred to $70 \%$ ethanol after a 24-h fixation in buffered formalin. Fixed tissues were then dehydrated in ethanol, cleared in xylene and embedded in paraffin blocks. Serial paraffin sections were cut from each block at $5 \mu \mathrm{m}$, deparaffinised with xylene, rehydrated through graded alcohols and stained with haematoxylin and eosin. Photographs of the stained sections were taken through a microscope and digitalised with a Nikon ECLIPSE 80i light microscope equipped with a computer-assisted morphometric system (Nikon Corporation). Villus height and crypt depth of ten well-preserved villi and crypts in each section were measured. The combined Alcian Blue-periodic acid-Schiff stain technique $^{(34)}$ was used to measure the intestinal goblet cell density. In detail, deparaffinised and rehydrated sections were stained with $1.0 \%$ Alcian Blue solution (Alcian Blue in 3\% acetic acid solution), gently washed in double-distilled water for $10 \mathrm{~min}$, oxidised in $1.0 \%$ periodic acid solution for $15 \mathrm{~min}$, 
Table 2. Sequences for real-time PCR primers

\begin{tabular}{|c|c|c|c|c|}
\hline Genes & Gene bank ID & Primer sequence, sense/antisense & Length (bp) & Efficiency (\%) \\
\hline TFF2 & XM_004934583.1 & $\begin{array}{l}\text { CCGAGTGAACTGTGGCTACC } \\
\text { TGGGGATGCAGGGGAGATA }\end{array}$ & 155 & 102 \\
\hline MUC2 & XM_001234581.3 & $\begin{array}{l}\text { AGGAATGGGCTGCAAGAGAC } \\
\text { GTGACATCAGGGCACACAGA }\end{array}$ & 77 & 99 \\
\hline TLR4 & NM_001030693.1 & $\begin{array}{l}\text { AGGCACCTGAGCTTTTCCTC } \\
\text { TACCAACGTGAGGTTGAGCC }\end{array}$ & 96 & 100 \\
\hline MyD88 & NM_001030962.1 & $\begin{array}{l}\text { ATCCGGACACTAGAGGGAGG } \\
\text { GGCAGAGCTCAGTGTCCATT }\end{array}$ & 115 & 101 \\
\hline$I F N-\gamma$ & NM_205149.1 & $\begin{array}{l}\text { CACTGACAAGTCAAAGCCGC } \\
\text { ACCTTCTTCACGCCATCAGG }\end{array}$ & 87 & 99 \\
\hline$I L-1 \beta$ & NM_204524.1 & $\begin{array}{l}\text { GTACCGAGTACAACCCCTGC } \\
\text { AGCAACGGGACGGTAATGAA }\end{array}$ & 112 & 98 \\
\hline IL-4 & NM_001007079.1 & $\begin{array}{l}\text { GTGCCCACGCTGTGCTTAC } \\
\text { AGGAAACCTCTCCCTGGATGTC }\end{array}$ & 82 & 102 \\
\hline IL-10 & NM_001004414.2 & $\begin{array}{l}\text { GGAGCTGAGGGTGAAGTTTGA } \\
\text { GACACAGACTGGCAGCCAAA }\end{array}$ & 129 & 102 \\
\hline OCLN & NM_205128.1 & $\begin{array}{l}\text { CCGTAACCCCGAGTTGGAT } \\
\text { ATTGAGGCGGTCGTTGATG }\end{array}$ & 214 & 97 \\
\hline CLDN2 & NM_001277622.1 & $\begin{array}{l}\text { CCTGCTCACCCTCATTGGAG } \\
\text { GCTGAACTCACTCTTGGGCT }\end{array}$ & 145 & 101 \\
\hline CLDN3 & NM_204202.1 & $\begin{array}{l}\text { CCCGTCCCGTTGTTGTTTTG } \\
\text { CCCCTTCAACCTTCCCGAAA }\end{array}$ & 126 & 98 \\
\hline$Z O-1$ & XM_413773.4 & $\begin{array}{l}\text { TGTAGCCACAGCAAGAGGTG } \\
\text { CTGGAATGGCTCCTTGTGGT }\end{array}$ & 159 & 102 \\
\hline$\beta$-Actin & NM_205518.1 & $\begin{array}{l}\text { TTGGTTTGTCAAGCAAGCGG } \\
\text { CCCCCACATACTGGCACTTT }\end{array}$ & 100 & 100 \\
\hline
\end{tabular}

TFF2, trefoil factor 2; MUC2, mucin 2; TLR4, toll-like receptor 4; MyD88, myeloid differentiation factor 88; IFN- $\gamma$, interferon- $\gamma$; OCLN, occludin; CLDN2, claudin-2; CLDN3, claudin-3; ZO-1, zonula occludens-1.

rinsed again in double-distilled water for $10 \mathrm{~min}$ and then placed in periodic acid-Schiff solution for $30 \mathrm{~min}$. Goblet cells were counted in five well-oriented villi per section, using the above-mentioned Nikon ECLIPSE 80i light microscope. Goblet cell density was measured as the goblet cell count divided by the corresponding villus length, averaged and expressed as goblet cell number per $100 \mu \mathrm{m}$ of villus length. All staining chemicals were sourced from Sigma-Aldrich Chemical.

\section{RNA isolation and mRNA quantification}

Total RNA in the snap-frozen mucosal samples (jejunal and ileal mucosa) were isolated using the TRIzol reagent kit (TaKaRa Biotechnology), according to the instructions of the manufacturer. The integrity of isolated RNA was examined by electrophoresis on a $1 \%$ agarose gel containing $0.5 \mathrm{mg} / \mathrm{ml}$ ethidium bromide, whereas the purity and concentration of RNA were quantified with a NanoDrop ND-1000 UV spectrophotometer (NanoDrop Technologies) according to OD260/ 280 readings. RNA samples were then diluted with diethyl pyrocarbonate-treated water (Biosharp) to a final concentration of $0.5 \mu \mathrm{g} / \mu \mathrm{l}$. Thereafter, $1 \mu \mathrm{g}$ of total RNA was reversetranscribed into complementary DNA using the PrimeScript ${ }^{\mathrm{TM}}$ RT reagent kit (TaKaRa Biotechnology) in the presence of random and oligo-dT primers, according to the manufacturer's protocol. The reverse transcription condition was set up as follows: $15 \mathrm{~min}$ at $37^{\circ} \mathrm{C}$ and $5 \mathrm{~s}$ at $85^{\circ} \mathrm{C}$. The primer sequences for the target and housekeeping genes (toll-like receptor 4 (TLR4), myeloid differentiation factor 88 (MyD88), IFN- $\gamma, I L-1 \beta$, $I L-4, \quad I L-10$, zonula occludens-1 (ZO-1), occludin (OCLN), claudin-2 (CLDN2), claudin-3 (CLDN3), trefoil factor 2 (TFF2),
MUC2 and $\beta$-actin) are available in the Table 2 . Each primer was tested for PCR amplification efficiency by determining a standard curve with complementary DNA dilutions, and the efficiency values were between 97 and 102\% (Table 2). Reverse transcription products (complementary DNA) were diluted 10× before real-time PCR assay. Real-time PCR was performed on an ABI StepOnePlus ${ }^{\mathrm{TM}}$ Real-Time PCR System (Applied Biosystems). The reaction mixture was composed of $2 \mu \mathrm{l}$ of complementary DNA, $0.4 \mu \mathrm{l}$ each of the forward and reverse primers, $10 \mu \mathrm{l}$ of SYBR Premix Ex Taq ${ }^{\mathrm{TM}}$ (TaKaRa Biotechnology), $0.4 \mu \mathrm{l}$ of ROX reference dye (TaKaRa Biotechnology) and $6 \cdot 8 \mu \mathrm{l}$ of double-distilled water. PCR procedures consisted of a pre-run at $95^{\circ} \mathrm{C}$ for $30 \mathrm{~s}$, forty cycles of denaturation at $95^{\circ} \mathrm{C}$ for $5 \mathrm{~s}$, followed by a $60^{\circ} \mathrm{C}$ annealing step for $30 \mathrm{~s}$. Melting curve conditions were as follows: one cycle of denaturation at $95^{\circ} \mathrm{C}$ for $10 \mathrm{~s}$, followed by an increase in temperature from 65 to $95^{\circ} \mathrm{C}$ with temperature change velocity at $0.5^{\circ} \mathrm{C} / \mathrm{s}$. The $2^{-\Delta \Delta C_{T}}$ method $^{(35)}$ was used to analyse the relative mRNA expression levels (fold changes), after normalisation against the reference gene $\beta$-actin, with the mRNA level of each target gene of broiler chickens in the control group being assigned as a value of 1 .

\section{Statistical analysis}

Data were analysed by one-way ANOVA using SPSS statistical software (version 16.0 for windows; SPSS Inc.) with pen (cage) as the experimental unit. Differences among treatments were examined using Tukey's multiple-range tests, and were considered to be significant when $P<0 \cdot 05$. Data were presented as means with their pooled standard errors. 


\section{Results}

\section{Growth performance}

Before LPS challenge (1-16 d of age), broilers exhibited (Table 3) similar growth performance (ADG, ADFI and F:G) among groups $(P>0 \cdot 05)$. Compared with the control group, LPS challenge reduced $A D G$ and $A D F I$, whereas it increased $F: G$ of broilers during $17-21 \mathrm{~d}$ of age $(P<0.05)$. In contrast, the $\mathrm{F}: \mathrm{G}$ of LPS-challenged broilers was decreased by L-Thr administration $(P<0.05)$, and its level in LPS-challenged broilers receiving $\mathrm{L}-\mathrm{Thr}$ administration was comparable with the control group $(P>0.05)$. The values of ADG and ADFI in LPS-challenged broilers fed a basal diet supplemented with L-Thr were intermediate, when compared with the other two groups $(P>0.05)$.

\section{Blood cell count}

LPS challenge resulted in increases in the numbers of leucocytes, mononuclear cells and neutrophils in the blood of broilers when compared with their unchallenged counterparts (Table 4, $P<0.05)$, with the counts of these aforementioned blood cells being intermediate in the $\mathrm{L}-\mathrm{Th}$ treatment group $(P>0.05)$. However, the counts of lymphocytes, eosinophils and erythrocytes in the blood were similar among treatments $(P>0.05)$.

Table 3. Effects of dietary L-threonine (L-Thr) supplementation on the growth performance of lipopolysaccharide (LPS)-challenged broilers

\begin{tabular}{|c|c|c|c|c|c|}
\hline \multirow[b]{2}{*}{ Items } & \multicolumn{3}{|c|}{ Treatments } & \multirow[b]{2}{*}{ SEM } & \multirow[b]{2}{*}{$P$} \\
\hline & CON & LPS & $\begin{array}{l}\text { LPS + } \\
\text { L-Thr }\end{array}$ & & \\
\hline \multicolumn{6}{|l|}{$1-16 d$} \\
\hline Average daily feed intake $(\mathrm{g} / \mathrm{d})$ & 34.34 & 36.09 & $36 \cdot 26$ & 0.67 & 0.458 \\
\hline Average daily gain $(g / d)$ & $27 \cdot 06$ & $27 \cdot 06$ & 28.83 & 0.33 & 0.054 \\
\hline Feed:gain ratio $(\mathrm{g}: \mathrm{g})$ & 1.27 & 1.33 & 1.26 & 0.02 & 0.130 \\
\hline \multicolumn{6}{|l|}{$17-21 \mathrm{~d}$} \\
\hline Average daily feed intake $(\mathrm{g} / \mathrm{d})$ & $87.83^{a}$ & $74.83^{b}$ & $80 \cdot 00^{a, b}$ & $2 \cdot 11$ & 0.016 \\
\hline Average daily gain $(\mathrm{g} / \mathrm{d})$ & $60 \cdot 33^{\mathrm{a}}$ & $44 \cdot 17^{b}$ & $53 \cdot 13^{\mathrm{a}, \mathrm{b}}$ & 2.45 & 0.006 \\
\hline Feed/gain ratio $(\mathrm{g}: \mathrm{g})$ & $1.46^{\mathrm{b}}$ & $1 \cdot 71^{\mathrm{a}}$ & $1.51^{\mathrm{b}}$ & 0.04 & 0.006 \\
\hline
\end{tabular}

CON, non-challenged broilers fed a basal diet; LPS, LPS-challenged broilers fed a basal diet; LPS + L-Thr, LPS-challenged broilers fed a basal diet supplemented with $3.0 \mathrm{~g} / \mathrm{kg} \mathrm{L}$-thr.

${ }^{a, b}$ Mean values within a row with unlike superscripts letters are significantly different $(P<0.05)$.

Table 4. Effects of dietary L-threonine (L-Thr) supplementation on blood cell composition of lipopolysaccharide (LPS)-challenged broilers

\begin{tabular}{|c|c|c|c|c|c|}
\hline \multirow[b]{2}{*}{ Items } & \multicolumn{3}{|c|}{ Treatments } & \multirow[b]{2}{*}{ SEM } & \multirow[b]{2}{*}{$P$} \\
\hline & CON & LPS & LPS + L-Thr & & \\
\hline Leucocytes $\left(10^{9} / I\right)$ & $33 \cdot 75^{\mathrm{b}}$ & $43 \cdot 82^{a}$ & $38 \cdot 37^{\mathrm{a}, \mathrm{b}}$ & 1.32 & $<0.001$ \\
\hline Lymphocytes $\left(10^{9} / \mathrm{l}\right)$ & $26 \cdot 16$ & 30.06 & 28.37 & 0.73 & 0.071 \\
\hline Mononuclear cells $\left(10^{9} / \mathrm{l}\right)$ & $0.14^{\mathrm{b}}$ & $0.20^{\mathrm{a}}$ & $0 \cdot 19^{a, b}$ & 0.01 & 0.049 \\
\hline Neutrophils $\left(10^{9} / \mathrm{l}\right)$ & $6 \cdot 19^{b}$ & $11 \cdot 30^{\mathrm{a}}$ & $8.99^{a, b}$ & 0.73 & 0.002 \\
\hline Eosinophils $\left(10^{9} / \mathrm{l}\right)$ & $1 \cdot 12$ & 1.24 & $1 \cdot 11$ & 0.03 & 0.240 \\
\hline Erythrocytes $\left(10^{12} / I\right)$ & $2 \cdot 01$ & 1.99 & $2 \cdot 01$ & 0.04 & 0.983 \\
\hline
\end{tabular}

CON, non-challenged broilers fed a basal diet; LPS, LPS-challenged broilers fed a basal diet; LPS + L-Thr, LPS-challenged broilers fed a basal diet supplemented with $3.0 \mathrm{~g} / \mathrm{kg} \mathrm{L-thr.}$

${ }^{a, b}$ Mean values within a row with unlike superscript letters are significantly different $(P<0.05)$.

\section{Inflammatory cytokine concentrations}

LPS challenge elevated concentrations of IL- $1 \beta$ and TNF- $\alpha$ in both serum and spleen, IFN- $\gamma$ in the jejunal mucosa and IL- $1 \beta$ in the ileal mucosa of broilers, when compared with the control group (Table $5, P<0 \cdot 05$ ). Supplementing L-Thr normalised the alteration in IL- $1 \beta$ concentration in the ileal mucosa of LPS-challenged broilers $(P<0 \cdot 05)$. Similarly, IFN- $\gamma$ level in the jejunal mucosa of LPS-challenged broilers was reduced by L-Thr supplementation $(P<0.05)$, but its value in the $\mathrm{L}$-Thr treatment group was still higher than that in the control group $(P<0.05)$. The values of serum IL- $1 \beta$ and serum and splenic TNF- $\alpha$ in the LPS-challenged broilers receiving $\mathrm{L}-\mathrm{Thr}$ administration were intermediate among groups $(P>0.05)$. Treatments did not alter the levels of IFN- $\gamma$ in the serum and spleen, IL- $1 \beta$ and TNF- $\alpha$ in the jejunal mucosa or IFN- $\gamma$ and TNF- $\alpha$ in the ileal mucosa $(P>0.05)$.

\section{Intestinal permeability, morphology and goblet cell density}

As shown in the Table 6, LPS injection increased circulating D-LA concentration of broilers when compared with the control group $(P<0.05)$, with the value being intermediate in the $\mathrm{L}-\mathrm{Thr}$ administration group in comparison with the other two groups $(P>0.05)$. However, treatments did not affect serum DAO activity $(P>0.05)$, even though it was numerically higher in the LPS-challenged broilers fed a basal diet. LPS challenge resulted in shorter villus height, lower ratio between villus height and crypt depth and lower goblet density in both jejunum and ileum $(P<0.05)$. In contrast, the supplementation of $\mathrm{L}$-Thr increased jejunal villus height, villus:crypt depth ratio in both jejunum and ileum and ileal goblet cell density of LPS-challenged broilers $(P<0.05)$; in addition, the levels of those parameters in the L-Thr treatment group were similar to those in the control group $(P>0 \cdot 05)$. Villus height in the ileum of LPS-challenged broilers

Table 5. Effects of dietary L-threonine (L-Thr) supplementation on cytokines concentrations in the serum and tissues of lipopolysaccharide (LPS)-challenged broilers

\begin{tabular}{|c|c|c|c|c|c|}
\hline \multirow[b]{2}{*}{ Items } & \multicolumn{3}{|c|}{ Treatments } & \multirow[b]{2}{*}{ SEM } & \multirow[b]{2}{*}{$P$} \\
\hline & $\mathrm{CON}$ & LPS & LPS + L-Thr & & \\
\hline \multicolumn{6}{|l|}{ Serum } \\
\hline IFN- $\gamma(\mathrm{ng} / \mathrm{l})$ & $180 \cdot 61$ & $189 \cdot 71$ & $206 \cdot 32$ & $9 \cdot 70$ & 0.596 \\
\hline $\mathrm{IL}-1 \beta$ (ng/l) & $17 \cdot 28^{b}$ & $26 \cdot 41^{\mathrm{a}}$ & $19 \cdot 94^{a, b}$ & 1.60 & 0.047 \\
\hline TNF- $a(\mathrm{ng} / \mathrm{l})$ & $116 \cdot 92^{b}$ & $145 \cdot 03^{a}$ & $122 \cdot 01^{a, b}$ & 4.60 & 0.018 \\
\hline \multicolumn{6}{|l|}{ Spleen } \\
\hline IFN- $\gamma$ (ng/g protein) & $7 \cdot 70$ & 9.03 & 7.98 & 0.25 & 0.085 \\
\hline IL-1 $\beta$ (ng/g protein) & $8.94^{\mathrm{b}}$ & $10 \cdot 10^{\mathrm{a}}$ & $10 \cdot 27^{\mathrm{a}}$ & 0.23 & 0.034 \\
\hline TNF- $a$ (ng/g protein) & $6 \cdot 47^{b}$ & $7 \cdot 55^{\mathrm{a}}$ & $7 \cdot 20^{\mathrm{a}, \mathrm{b}}$ & 0.17 & 0.020 \\
\hline \multicolumn{6}{|l|}{ Jejunal mucosa } \\
\hline IFN- $\gamma$ (ng/g protein) & $4.06^{c}$ & $6 \cdot 93^{\mathrm{a}}$ & $4.98^{\mathrm{b}}$ & 0.37 & $<0.001$ \\
\hline IL-1 $\beta$ (ng/g protein) & $5 \cdot 73$ & $7 \cdot 19$ & $6 \cdot 11$ & 0.28 & 0.079 \\
\hline TNF-a (ng/g protein) & 3.98 & $4 \cdot 38$ & 4.42 & 0.16 & 0.507 \\
\hline \multicolumn{6}{|l|}{ Ileal mucosa } \\
\hline IFN- $\gamma$ (ng/g protein) & 5.05 & 5.03 & $5 \cdot 26$ & 0.21 & 0.896 \\
\hline IL-1 $\beta$ (ng/g protein) & $6 \cdot 13^{b}$ & $8.55^{\mathrm{a}}$ & $6.66^{\mathrm{b}}$ & 0.33 & 0.001 \\
\hline TNF- $a$ (ng/g protein) & 4.73 & 4.35 & 4.55 & 0.14 & 0.550 \\
\hline
\end{tabular}

IFN- $\gamma$, interferon- $\gamma$; CON, non-challenged broilers fed a basal diet; LPS, LPSchallenged broilers fed a basal diet; LPS + L-Thr, LPS-challenged broilers fed a basal diet supplemented with $3.0 \mathrm{~g} / \mathrm{kg} \mathrm{L-thr.}$

a,b,c Mean values within a row with unlike superscripts are significantly different $(P<0.05)$. 
Table 6. Effects of dietary L-threonine (L-Thr) supplementation on serum diamine oxidase activity and D-lactic acid concentration, intestinal morphology and goblet cell density of lipopolysaccharide (LPS)-challenged broilers

\begin{tabular}{|c|c|c|c|c|c|}
\hline \multirow[b]{2}{*}{ Items } & \multicolumn{3}{|c|}{ Treatments } & \multirow[b]{2}{*}{ SEM } & \multirow[b]{2}{*}{$P$} \\
\hline & CON & LPS & LPS + L-Thr & & \\
\hline \multicolumn{6}{|l|}{ Serum } \\
\hline Diamine oxidase $(\mathrm{U} / \mathrm{ml})$ & $19 \cdot 70$ & 36.97 & 19.35 & 3.49 & 0.074 \\
\hline D-lactic acid (mmol/l) & $1 \cdot 10^{\mathrm{b}}$ & $1.53^{\mathrm{a}}$ & $1 \cdot 23^{\mathrm{a}, \mathrm{b}}$ & 0.08 & 0.045 \\
\hline \multicolumn{6}{|l|}{ Jejunum } \\
\hline Villus height $(\mu \mathrm{m})$ & $1579 \cdot 21^{a}$ & $1410 \cdot 43^{b}$ & $1520 \cdot 91^{a}$ & $20 \cdot 88$ & $<0.001$ \\
\hline Crypt depth $(\mu \mathrm{m})$ & $270 \cdot 36$ & 274.97 & 258.92 & $4 \cdot 21$ & 0.292 \\
\hline Villus height:crypt depth & $5 \cdot 87^{\mathrm{a}}$ & $5 \cdot 14^{\mathrm{b}}$ & $5.88^{\mathrm{a}}$ & $0 \cdot 11$ & 0.003 \\
\hline Goblet cell density ( $n / 100 \mu \mathrm{m}$ villus height) & $25 \cdot 31^{\mathrm{a}}$ & $18 \cdot 44^{\mathrm{b}}$ & $19.09^{b}$ & 0.83 & $<0.001$ \\
\hline \multicolumn{6}{|l|}{ lleum } \\
\hline Villus height $(\mu \mathrm{m})$ & $1122 \cdot 57^{\mathrm{a}}$ & $1010 \cdot 25^{b}$ & $1060 \cdot 89^{\mathrm{a}, \mathrm{b}}$ & $15 \cdot 79$ & 0.008 \\
\hline Crypt depth $(\mu \mathrm{m})$ & 232.99 & $248 \cdot 12$ & $237 \cdot 20$ & 2.74 & 0.088 \\
\hline Villus height:crypt depth & $4.82^{\mathrm{a}}$ & $4.09^{\mathrm{b}}$ & $4.48^{\mathrm{a}}$ & 0.12 & $<0.001$ \\
\hline Goblet cell density ( $n / 100 \mu \mathrm{m}$ villus height) & $11.51^{\mathrm{a}}$ & $7.89^{b}$ & $10 \cdot 82^{\mathrm{a}}$ & 0.40 & $<0.001$ \\
\hline
\end{tabular}

CON, non-challenged broilers fed a basal diet; LPS, LPS-challenged broilers fed a basal diet; LPS +L-Thr, LPS-challenged broilers fed a basal diet supplemented with $3.0 \mathrm{~g} / \mathrm{kg} \mathrm{L}$-thr.

${ }^{\mathrm{a}, \mathrm{b}}$ Mean values within a row with unlike superscripts are significantly different $(P<0.05)$.

receiving $\mathrm{L}$-Thr was intermediate among the three groups $(P>0.05)$. However, birds exhibited similar crypt depth in the jejunum and ileum among treatments $(P>0 \cdot 05)$.

\section{Gene expressions}

Compared with the control group (Table 7), LPS challenge increased mRNA abundances of $M U C 2, C L D N 3, T L R 4$ and $I F N-\gamma$ in the jejunal mucosa, and $I L-1 \beta$ mRNA expression level in the ileal mucosa, whereas it decreased the mRNA expression abundance of $Z O-1$ in the ileal mucosa $(P<0 \cdot 05)$. The altered mRNA expressions of these aforementioned genes were reversed with $\mathrm{L}-\mathrm{Thr}$ administration $(P<0 \cdot 05)$. However, treatments did not alter mRNA expression level of TFF2, OCLN, $C L D N 2, M y D 88, I L-4$ or $I L-10$ in the intestinal mucosa $(P>0.05)$.

\section{Discussion}

Numerous studies have proven that LPS challenge would lead to compromised growth performance of broilers ${ }^{(3,5,32,36,37)}$, and we once again confirmed its harmful consequences on growth performance of broilers in this study, as evidenced by reduced weight gain and feed conversion efficiency. The impaired growth performance of LPS-challenged broilers is attributable to reduced appetite ${ }^{(38)}$, disrupted gut barrier function ${ }^{(4,10)}$, impaired nutrient adsorption ${ }^{(7)}$ and especially the diversion of nutrients away from growth in support of various immune-related processes as the synthesis of various acute proteins and cytokines $^{(39)}$. Thr requirement of broilers would increase when exposed to pathogenic bacterial challenges. Star et al. ${ }^{(26)}$ have shown that a higher dietary Thr:Lys ratio improves growth performance of broilers during subclinical infection with Clostridium perfringens. Dietary $\mathrm{Thr}$ supplementation also improves growth performance of broilers challenged with Eimeria maxima ${ }^{(23)}$. In this study, the compromised growth performance of LPS-challenged broilers was alleviated with the supplementation of $\mathrm{L}$-Thr, when referring to the improved feed utilisation efficiency of LPS-challenged broilers after L-Thr
Table 7. Effects of dietary L-threonine (L-Thr) supplementation on the gene expressions in the intestinal mucosa of lipopolysaccharide (LPS)challenged broilers

\begin{tabular}{|c|c|c|c|c|c|}
\hline \multirow[b]{2}{*}{ Items } & \multicolumn{3}{|c|}{ Treatments } & \multirow[b]{2}{*}{ SEM } & \multirow[b]{2}{*}{$P$} \\
\hline & $\mathrm{CON}$ & LPS & LPS + L-Thr & & \\
\hline \multicolumn{6}{|l|}{ Jejunum } \\
\hline MUC2 & $1.00^{b}$ & $1.54^{\mathrm{a}}$ & $0.94^{b}$ & 0.08 & 0.001 \\
\hline TFF2 & 1.00 & 1.00 & 0.99 & 0.09 & 0.999 \\
\hline$O C L N$ & 1.00 & $1 \cdot 13$ & 0.90 & 0.08 & 0.551 \\
\hline CLDN2 & 1.00 & 1.11 & 0.94 & 0.06 & 0.475 \\
\hline CLDN3 & $1.00^{\mathrm{b}}$ & $1.34^{a}$ & $0.89^{b}$ & 0.07 & 0.006 \\
\hline$Z O-1$ & 1.00 & 0.88 & 0.82 & 0.06 & 0.518 \\
\hline TLR4 & $1.00^{b}$ & $1.44^{\mathrm{a}}$ & $1 \cdot 12^{b}$ & 0.08 & 0.043 \\
\hline MyD88 & 1.00 & 1.39 & 1.17 & 0.12 & 0.445 \\
\hline IFN- $-\gamma$ & $1.00^{\mathrm{b}}$ & $1.47^{\mathrm{a}}$ & $1.01^{\mathrm{b}}$ & 0.09 & 0.037 \\
\hline$I L-1 \beta$ & 1.00 & $1 \cdot 14$ & 0.90 & 0.09 & 0.544 \\
\hline$I L-4$ & 1.00 & 0.78 & 0.79 & 0.09 & 0.584 \\
\hline IL-10 & 1.00 & 0.83 & 0.64 & 0.07 & 0.103 \\
\hline \multicolumn{6}{|l|}{ Ileum } \\
\hline MUC2 & 1.00 & 0.91 & 0.96 & 0.08 & 0.921 \\
\hline TFF2 & 1.00 & 1.09 & 1.08 & 0.09 & 0.906 \\
\hline OCLN & 1.00 & 0.85 & 1.07 & 0.07 & 0.428 \\
\hline CLDN2 & 1.00 & 1.00 & $1 \cdot 10$ & 0.06 & 0.772 \\
\hline$C L D N 3$ & 1.00 & 1.10 & 1.20 & 0.05 & 0.349 \\
\hline $2 O-1$ & $1.00^{\mathrm{a}}$ & $0.69^{b}$ & $0.99^{a}$ & 0.06 & 0.028 \\
\hline TLR4 & 1.00 & 0.81 & 1.06 & $0 \cdot 10$ & 0.597 \\
\hline MyD88 & 1.00 & 1.01 & 1.23 & 0.08 & 0.495 \\
\hline IFN- $-\gamma$ & 1.00 & 1.00 & 1.09 & 0.07 & 0.872 \\
\hline$I L-1 \beta$ & $1.00^{\mathrm{b}}$ & $1.42^{\mathrm{a}}$ & $0.88^{\mathrm{b}}$ & 0.08 & 0.008 \\
\hline IL-4 & 1.00 & 0.98 & 1.08 & 0.12 & 0.945 \\
\hline$I L-10$ & 1.00 & $1 \cdot 15$ & 1.02 & 0.09 & 0.770 \\
\hline
\end{tabular}

CON, non-challenged broilers fed a basal diet; LPS, LPS-challenged broilers fed a basal diet; LPS + L-Thr, LPS-challenged broilers fed a basal diet supplemented with $3.0 \mathrm{~g} / \mathrm{kg}$ L-thr; $M U C 2$, mucin 2; TFF2, trefoil factor 2; OCLN, occludin; CLDN2, claudin-2; CLDN3, claudin-3; ZO-1, zonula occludens-1; TLR4, toll-like receptor 4; $M y D 88$, myeloid differentiation factor 88; IFN- $\gamma$, interferon- $\gamma$.

a,b Mean values within a row with unlike superscripts are significantly different $(P<0.05)$.

administration. These results, in turn, indicated that the requirement of Thr in the LPS-challenged broilers also elevated.

Immune cell distribution in the blood is sensitive to immunological stress ${ }^{(40)}$. Shen et al. $^{(41)}$ have observed higher counts of leucocytes and lymphocytes in blood of LPS-treated 
broilers. Similarly, Li et al. ${ }^{(5)}$ have reported that LPS challenge elevates the numbers of leucocytes in broilers. LPS injection increased the number of leucocytes, mononuclear cells and neutrophils, suggesting that LPS challenge induced inflammatory response in blood in this study. In this experiment, LPS challenge also increased pro-inflammatory cytokine levels in serum, spleen and intestinal mucosa, with the protein concentrations of mucosal cytokines being in parallel with their mRNA expression levels. The similar results are also observed by Wang et al. ${ }^{(42)}$ and Wu et $a l .{ }^{(11)}$ in LPS-challenged broilers. TLR4 serves as a signalling receptor for $\operatorname{LPS}^{(43,44)}$, and its activation by LPS results in the release of critical pro-inflammatory cytokines ${ }^{(2)}$. In our study, the mRNA abundance of jejunal TLR4 was promoted with LPS challenge, implying that the activation of TLR4 was also involved in the regulation of pro-inflammatory cytokine synthesis in this study. Mucins such as MUC2 have immunoregulatory effects on the gut, and it could interfere with antigen-sampling dendritic cell expression of inflammatory cytokine by inhibiting gene transcription through NF- $\kappa \mathrm{B}^{(45)}$. In mammals, studies have shown that intestinal inflammation would increase gastrointestinal Thr uptake and mucin synthesis, and luminal Thr concentration acutely affects mucin synthesis ${ }^{(46-48)}$. These findings together suggest that Thr could modulate gut inflammatory reaction by regulating mucin synthesis. In addition, the key role that Thr plays in the synthesis of Ig, antibodies and other immune-related proteins also enables Thr to regulate immune system $^{(27,49-51)}$. In a chicken intestinal ex vivo model, Zhang et $a l^{(30)}$ have shown that a 2 -h Thr withdrawal in the culture medium induces compensatory increases in the mRNA abundances of $I L-8$ and $I g A$ when exposed to LPS challenge, and these increases are inhibited with Thr supplementation. Similarly, we showed that dietary L-Thr supplementation alleviated the inflammatory responses in LPS-challenged broilers, as evidenced by the decreases in pro-inflammatory cytokines (IL- $1 \beta$ and $\mathrm{IFN}-\gamma$ ) at both protein and transcription levels in the intestinal mucosa of LPS-challenged broilers receiving L-Thr. The inhibitory effects of dietary L-Thr supplementation on pro-inflammatory cytokine synthesis have also been reported in the intestine of broilers challenged with coccidiosis ${ }^{(23)}$, and weaned piglets challenged with Escherichia coli $\mathrm{K}^{+8^{+(52)}}$. In our study, the decreases in protein and transcription levels of pro-inflammatory cytokines in the intestine of broilers receiving $\mathrm{L}$-Thr administration was in accordance with their simultaneously reduced intestinal TLR 4 mRNA abundance, implying that L-Thr may inhibit the synthesis of cytokines by inactivating TLR4.

Plasma D-LA, a product of bacterial fermentation of carbohydrates, is a sensitive marker to reflect intestinal injury and to monitor intestinal permeability ${ }^{(53)}$. In this study, LPS challenge increased circulating D-LA level, impaired intestinal morphology and disrupted the mRNA expressions of intestinal tight junctions (increased mRNA expression of CLDN3, whereas reduced ZO-1 mRNA level), indicating that LPS challenge impaired intestinal barrier function. Similarly, oral administration of LPS impairs gut barrier function of broilers at an early age, as demonstrated by higher circulating D-LA level and DAO activity $^{(11)}$. Our previous study has also shown that intraperitoneal LPS injection damages intestinal barrier function of young broilers, according to the elevated plasma DAO activity, impaired intestinal morphology and disordered expressions of intestinal tight-junction proteins ${ }^{(4)}$. The damaged intestinal barrier function of LPS-challenged broilers in this study is supposed to be associated with the simultaneous activation of TLR 4 and promoted pro-inflammatory cytokine synthesis. LPS could result in an increase in intestinal permeability in vitro and in vivo by inducing enterocyte membrane expression and localisation of TLR4 ${ }^{(54)}$. In addition, previous studies have evidenced that the pro-inflammatory cytokines such as IL- $1 \beta$ and IFN- $\gamma$ would impair intestinal tight junction and increase gut permeability ${ }^{(55,56)}$. It is interesting to observe that the intestinal tight-junction proteins $C L D N 3$ and $Z O-1$ exhibit opposite response to LPS challenge in this study. Tight junctions, the multi-protein complexes, are composed of transmembrane proteins, peripheral membrane (scaffolding) proteins and regulatory molecules including kinases, among which CLDN family proteins are the most important of the transmembrane proteins, whereas ZO family proteins are peripheral membrane proteins and are crucial to tight-junction assembly ${ }^{(57)}$. The increased CLDN3 mRNA expression is therefore thought to be associated with compensatory reaction, whereas the decreased mRNA level of ZO-1 is likely owing to the possible loss of tight junctions. Similar results are also reported previously in vivo ${ }^{(4)}$ and in vitro ${ }^{(58)}$. In an in vitro study, Smirnova et al. ${ }^{(59)}$ have found that LPS up-regulates mRNA expression and secretion of mucin and cytokine in goblet cells in a concentration- and timedependent manner. In this study, LPS challenge also elevated mRNA expression level of $M U C 2$ in jejunal mucosa, which was in agreement with the finding of Zhang et $a l .{ }^{(30)}$. The increased MUC2 mRNA level may be due to a kappa $\mathrm{B}$ site in the 5'-flanking region of the MUC2 gene that can activate MUC2 transcription, and the elevated pro-inflammatory cytokine levels, as summarised by Andrianifahanana et al. ${ }^{(60)}$. In our study, the intestinal goblet cell density of broiler chickens was reduced by LPS challenge, suggesting that LPS challenge interfered with the differentiation of goblet cells. Studies have shown that LPS-induced matrix metalloproteinase-9 and TLR4 activation are involved in the inhibition of goblet cell differentiation $^{(61,62)}$. Considering the key roles goblet cell and MUC2 play in the gut barrier maintenance ${ }^{(63)}$, the regulatory effects of LPS on goblet cell density and MUC2 transcription may also contribute to the impaired intestinal barrier function of LPS-challenged broilers in this study. It has been reported that dietary $\mathrm{Thr}$ requirement for broilers to acquire the optimal intestinal morphology is $125 \%$ of NRC recommendation ${ }^{(28)}$. Zhang et al. ${ }^{(22)}$ observed that a higher level of $\mathrm{Thr}$ diet decreased gut permeability and improved intestinal morphology of broilers exposed to the combined feed withdrawal and coccidial vaccine challenge. Similarly, Wils-Plotz et al. ${ }^{(23)}$ reported that dietary $\mathrm{Thr}$ addition ameliorated the impaired barrier function of broilers challenged with E. maxima. In our study, we found that L-Thr supplementation improved intestinal morphology and normalised mRNA expressions of intestinal tight-junction proteins in LPS-challenged broilers, suggesting that L-Thr supplementation improved intestinal barrier function of broilers challenged with LPS. The improvements in the intestinal barrier function of LPS-challenged broilers receiving the L-Thr were in parallel with their reduced gut 
pro-inflammatory cytokines at both protein and transcription levels, as well as the decreased intestinal TLR 4 mRNA expression level, which in turn revealed that $\mathrm{L}$-Thr supplementation may improve the gut barrier function by inhibiting the synthesis of pro-inflammatory cytokines, and by inactivating TLR4 signal. Dietary Thr level is extremely vital for goblet cell differentiation and mucin synthesis, which are two critical components of the intestinal barrier ${ }^{(17,18,20,21)}$. In this study, L-Thr supplementation increased the ileal goblet cell density of LPS-challenged broilers, and this may be owing to a higher level of Thr requirement for the differentiation of goblet cell in LPS-challenged broilers. Zhang et al. ${ }^{(30)}$ have found that Thr addition normalises the mRNA expression level of MUC2 in an ex vivo chicken ileal explant under LPS exposure. The alteration in the jejunal $M U C 2$ mRNA abundance of LPS-challenged broilers was also reversed when supplementing L-Thr in this study. In this way, the regulatory effects of $\mathrm{L}$-Thr on intestinal goblet cell density and MUC2 mRNA expression would be therefore closely associated with the improved barrier function of LPS-challenged broilers receiving $\mathrm{L}$-Thr administration.

In conclusion, our results suggested that the dietary L-Thr supplementation at a dosage of $3.0 \mathrm{~g} / \mathrm{kg}$ could alleviate the harmful consequences of LPS challenge on growth performance, inflammatory responses and intestinal barrier function of broilers receiving a basal diet, in which Thr level met NRC requirement of broiler chickens.

\section{Acknowledgements}

The technical assistance of the labmates is gratefully acknowledged.

This study was funded by the China Postdoctoral Science Foundation (grant no. 2017M621765).

The contributions of the authors are as follows: Y. Chen and Y. Z. designed the study. Y. Chen, H. Z. and Y. Cheng participated in the animal experiment. Y. Chen, H. Z., Y. Cheng, Y. L. and C. W. conducted the research. Y. Chen, H. Z., Y. Cheng and Y. L. analysed the data. Y. Chen discussed the results and wrote the paper. All authors read and approved the final manuscript.

The authors declare that there are no conflicts of interest.

\section{References}

1. Alexander C \& Rietschel ET (2001) Invited review: bacterial lipopolysaccharides and innate immunity. J Endotoxin Res 7, 167-202

2. Lu YC, Yeh WC \& Ohashi PS (2008) LPS/TLR4 signal transduction pathway. Cytokine 42, 145-151.

3. Tan J, Liu S, Guo Y, et al. (2014) Dietary l-arginine supplementation attenuates lipopolysaccharide-induced inflammatory response in broiler chickens. Br J Nutr 111, 1394-1404.

4. Li Y, Zhang H, Chen YP, et al. (2015) Bacillus amyloliquefaciens supplementation alleviates immunological stress and intestinal damage in lipopolysaccharide-challenged broilers. Anim Feed Sci Technol 208, 119-131.

5. Li Y, Zhang H, Chen YP, et al. (2015) Bacillus amyloliquefaciens supplementation alleviates immunological stress in lipopolysaccharide-challenged broilers at early age. Poult Sci 94, 1504-1511
6. Liu L, Shen J, Zhao C, et al. (2015) Dietary Astragalus polysaccharide alleviated immunological stress in broilers exposed to lipopolysaccharide. Int J Biol Macromol 72, 624-632.

7. Zhang X, Zhao L, Cao F, et al. (2013) Effects of feeding fermented Ginkgo biloba leaves on small intestinal morphology, absorption, and immunomodulation of early lipopolysaccharide-challenged chicks. Poult Sci 92, 119-130.

8. Kaiser MG, Block SS, Ciraci C, et al. (2012) Effects of dietary vitamin $\mathrm{E}$ type and level on lipopolysaccharide-induced cytokine mRNA expression in broiler chicks. Poult Sci 91, 1893-1898.

9. Gilani S, Howarth GS, Kitessa SM, et al. (2016) New biomarkers for intestinal permeability induced by lipopolysaccharide in chickens. Anim Product Sci 56, 1984-1997.

10. Groschwitz KR \& Hogan SP (2009) Intestinal barrier function: molecular regulation and disease pathogenesis. J Allergy Clin Immunol 124, 3-20.

11. Wu QJ, Zhou YM, Wu YN, et al. (2013) The effects of natural and modified clinoptilolite on intestinal barrier function and immune response to LPS in broiler chickens. Vet Immunol Immunopathol 153, 70-76.

12. Tenenhouse HS \& Deutsch HF (1966) Some physical-chemical properties of chicken $\gamma$-globulins and their pepsin and papain digestion products. Immunochemistry 3, 11-20.

13. Schaart MW, Schierbeek H, van der Schoor SRD, et al. (2005) Threonine utilization is high in the intestine of piglets. $J$ Nutr 135, 765-770.

14. van der Schoor SRD, Wattimena DL, Huijmans J, et al. (2007) The gut takes nearly all: threonine kinetics in infants. $A m J$ Clin Nutr 86, 1132-1138.

15. Floc'h NL \& Sève B (2007) Catabolism through the threonine dehydrogenase pathway does not account for the high firstpass extraction rate of dietary threonine by the portal drained viscera in pigs. Br J Nutr $\mathbf{9 3}, 447-456$.

16. van der Sluis M, Schaart MW, de Koning BA, et al. (2009) Threonine metabolism in the intestine of mice: loss of mucin 2 induces the threonine catabolic pathway. J Pediatr Gastroenterol Nutr 49, 99-107.

17. Wang W, Zeng X, Mao X, et al. (2010) Optimal dietary true ileal digestible threonine for supporting the mucosal barrier in small intestine of weanling pigs. J Nutr 140, 981-986.

18. Law GK, Bertolo RF, Adjiri-Awere A, et al. (2007) Adequate oral threonine is critical for mucin production and gut function in neonatal piglets. Am J Physiol Gastrointest Liver Physiol 292, G1293-G1301.

19. Hamard A, Mazurais D, Boudry G, et al. (2010) A moderate threonine deficiency affects gene expression profile, paracellular permeability and glucose absorption capacity in the ileum of piglets. J Nutr Biochem 21, 914-921.

20. Chee SH, Iji PA, Choct M, et al. (2010) Functional interactions of manno-oligosaccharides with dietary threonine in chicken gastrointestinal tract. I. Growth performance and mucin dynamics. Br Poult Sci 51, 658-666.

21. Chee SH, Iji PA, Choct M, et al. (2010) Functional interactions of manno-oligosaccharides with dietary threonine in chicken gastrointestinal tract. II. Mucosal development, mucin dynamics and nutrient utilisation. Br Poult Sci 51, 667-676.

22. Zhang Q, Chen X, Eicher SD, et al. (2016) Effect of threonine deficiency on intestinal integrity and immune response to feed withdrawal combined with coccidial vaccine challenge in broiler chicks. Br J Nutr 116, 2030-2043.

23. Wils-Plotz EL, Jenkins MC \& Dilger RN (2013) Modulation of the intestinal environment, innate immune response, and barrier function by dietary threonine and purified fiber during a coccidiosis challenge in broiler chicks. Poult Sci $\mathbf{9 2}$, $735-745$. 
24. National Research Council (1994) Nutrient Requirements of Poultry, 9th rev. ed. Washington, DC: National Academies Press.

25. Corzo A, Kidd MT, Dozier IWA, et al. (2007) Dietary threonine needs for growth and immunity of broilers raised under different litter conditions. J Appl Poult Res 16, 574-582.

26. Star L, Rovers M, Corrent E, et al. (2012) Threonine requirement of broiler chickens during subclinical intestinal Clostridium infection. Poult Sci 91, 643-652.

27. Taghinejad-Roudbaneh M, Babaee MJ, Afrooziyeh M, et al. (2013) Estimation of dietary threonine requirement for growth and immune responses of broilers. J Appl Anim Res 41, 474-483.

28. Min YN, Liu SG, Qu ZX, et al. (2017) Effects of dietary threonine levels on growth performance, serum biochemical indexes, antioxidant capacities, and gut morphology in broiler chickens. Poult Sci 96, 1290-1297.

29. Chen YP, Cheng YF, Li XH, et al. (2017) Effects of threonine supplementation on the growth performance, immunity, oxidative status, intestinal integrity, and barrier function of broilers at the early age. Poult Sci 96, 405-413.

30. Zhang Q, Chen X, Eicher SD, et al. (2017) Effect of threonine on secretory immune system using a chicken intestinal ex vivo model with lipopolysaccharide challenge. Poult Sci 96, 3043-3051.

31. Gonzalez D, Mustacich DJ, Traber MG, et al. (2011) Early feeding and dietary lipids affect broiler tissue fatty acids, vitamin $\mathrm{E}$ status, and cyclooxygenase- 2 protein expression upon lipopolysaccharide challenge. Poult Sci 90, 2790-2800.

32. Wang X, Li Y, Shen J, et al. (2015) Effect of Astragalus polysaccharide and its sulfated derivative on growth performance and immune condition of lipopolysaccharide-treated broilers. Int J Biol Macromol 76, 188-194.

33. Hosoda N, Nishi M, Nakagawa M, et al. (1989) Structural and functional alterations in the gut of parenterally or enterally fed rats. J Surg Res 47, 129-133.

34. Horn NL, Donkin SS, Applegate TJ, et al. (2009) Intestinal mucin dynamics: response of broiler chicks and White Pekin ducklings to dietary threonine. Poult Sci 88, 1906-1914.

35. Livak KJ \& Schmittgen TD (2001) Analysis of relative gene expression data using real-time quantitative pcr and the $2^{-\Delta \Delta C T}$ Method. Methods 25, 402-408.

36. Zheng XC, Wu QJ, Song ZH, et al. (2016) Effects of Oridonin on growth performance and oxidative stress in broilers challenged with lipopolysaccharide. Poult Sci 95, 2281-2289.

37. Zhang X, Zhong X, Zhou Y, et al. (2010) Dietary RRR- $\alpha$ tocopherol succinate attenuates lipopolysaccharide-induced inflammatory cytokines secretion in broiler chicks. Br J Nutr 104, 1796-1805.

38. Vichaya EG, Hunt SC \& Dantzer R (2014) Lipopolysaccharide reduces incentive motivation while boosting preference for high reward in mice. Neuropsychopharmacology 39, 2884-2890.

39. Spurlock ME (1997) Regulation of metabolism and growth during immune challenge: an overview of cytokine function. J Anim Sci 75, 1773-1783.

40. Dhabhar FS, Miller AH, McEwen BS, et al. (1995) Effects of stress on immune cell distribution. Dynamics and hormonal mechanisms. J Immunol 154, 5511.

41. Shen YB, Piao XS, Kim SW, et al. (2010) The effects of berberine on the magnitude of the acute inflammatory response induced by Escherichia coli lipopolysaccharide in broiler chickens. Poult Sci 89, 13-19.

42. Wang X, Shen J, Li S, et al. (2014) Sulfated Astragalus polysaccharide regulates the inflammatory reaction in LPS-infected broiler chicks. Int J Biol Macromol 69, 146-150.
43. Beutler B (2000) Tlr4: central component of the sole mammalian LPS sensor. Curr Opin Immunol 12, 20-26.

44. Miller SI, Ernst RK \& Bader MW (2005) LPS, TLR4 and infectious disease diversity. Nat Rev Microbiol 3, 36-46.

45. Shan M, Gentile M, Yeiser JR, et al. (2013) Mucus enhances gut homeostasis and oral tolerance by delivering immunoregulatory signals. Science 342, 447-453.

46. Nichols NL \& Bertolo RF (2008) Luminal Threonine concentration acutely affects intestinal mucosal protein and mucin synthesis in piglets. J Nutr 138, 1298-1303.

47. Faure M, Choné F, Mettraux C, et al. (2007) Threonine utilization for synthesis of acute phase proteins, intestinal proteins, and mucins is increased during sepsis in rats. J Nutr 137, 1802-1807.

48. Rémond D, Buffière C, Godin JP, et al. (2009) Intestinal inflammation increases gastrointestinal threonine uptake and mucin synthesis in enterally fed minipigs. J Nutr 139, 720-726.

49. Li P, Yin YL, Li D, et al. (2007) Amino acids and immune function. Br J Nutr 98, 237-252.

50. Wang X, Qiao SY, Liu M, et al. (2006) Effects of graded levels of true ileal digestible threonine on performance, serum parameters and immune function of $10-25 \mathrm{~kg}$ pigs. Anim Feed Sci Technol 129, 264-278.

51. Defa L, Changting X, Shiyan Q, et al. (1999) Effects of dietary threonine on performance, plasma parameters and immune function of growing pigs. Anim Feed Sci Technol 78, 179-188.

52. Ren M, Liu XT, Wang X, et al. (2014) Increased levels of standardized ileal digestible threonine attenuate intestinal damage and immune responses in Escherichia coli $\mathrm{K}^{+} 8^{+}$ challenged weaned piglets. Anim Feed Sci Technol 195, 67-75.

53. Sun XQ, Fu XB, Rong Z, et al. (2001) Relationship between plasma $\mathrm{D}(-)$-lactate and intestinal damage after severe injuries in rats. World J Gastroenterol 7, 555-558.

54. Guo S, Al-Sadi R, Said HM, et al. (2013) Lipopolysaccharide causes an increase in intestinal tight junction permeability in vitro and in vivo by inducing enterocyte membrane expression and localization of TLR-4 and CD14. Am J Pathol 182, 375-387.

55. Capaldo CT \& Nusrat A (2009) Cytokine regulation of tight junctions. Biochim Biophys Acta 1788, 864-871.

56. Al-Sadi R, Ye D, Dokladny K, et al. (2008) Mechanism of IL-1 $\beta$-induced increase in intestinal epithelial tight junction permeability. J Immunol 180, 5653-5661.

57. Turner JR (2009) Intestinal mucosal barrier function in health and disease. Nat Rev Immunol 9, 799-809.

58. Bein A, Zilbershtein A, Golosovsky M, et al. (2017) LPS induces hyper-permeability of intestinal epithelial cells. J Cell Physiol 232, 381-390.

59. Smirnova MG, Guo L, Birchall JP, et al. (2003) LPS up-regulates mucin and cytokine mRNA expression and stimulates mucin and cytokine secretion in goblet cells. Cell Immunol 221, 42-49.

60. Andrianifahanana M, Moniaux N \& Batra SK (2006) Regulation of mucin expression: mechanistic aspects and implications for cancer and inflammatory diseases. Biochim Biophys Acta 1765, 189-222.

61. Garg P, Ravi A, Patel NR, et al. (2007) Matrix metalloproteinase-9 regulates muc-2 expression through its effect on goblet cell differentiation. Gastroenterology 132, 1877-1889.

62. Sodhi CP, Neal MD, Siggers R, et al. (2012) Intestinal epithelial toll-like receptor 4 regulates goblet cell development and is required for necrotizing enterocolitis in mice. Gastroenterology 143, 708-718.e705.

63. Kim YS \& Ho SB (2010) Intestinal goblet cells and mucins in health and disease: recent insights and progress. Curr Gastroenterol Rep 12, 319-330. 